\title{
ANALISIS PROSES PEMECAHAN MASALAH GEOMETRI BERDASARKAN TEORI VAN HIELE
}

\author{
Marlinda Indah Eka Budiarti \\ Universitas Muhammadiyah Sorong \\ e-mail: indah.eka43@gmail.com
}

\begin{abstract}
This study aims to explore and describe the process of problem solving geometry reach the level of visualization based on the Van Hiele theory. This type of research is descriptive explorative and qualitative approach. Subject of the study was obtained from the high school students who were tested on the level of Van Hiele geometry. Each level of visualization. The results of this study indicate that solving problems in geometry learners who attained think visualization is to identify problems and set goals using the language question.
\end{abstract}

Keywords: problem-solving process, geometry, Van Hiele levels of thinking

\section{PENDAHULUAN}

\section{Latar Belakang}

Matematika merupakan ilmu dasar yang mempunyai peranan penting dalam kehidupan sehari-hari maupun dalam pengembangan ilmu dan teknologi (Saragih \& Habeahan, 2014; Bahmaei, 2014; Mohamed \& Waheed, 2011). Salah satu cabang matematika yang harus dikuasai peserta didik yaitu geometri. Tujuan pembelajaran geometri adalah agar peserta didik memiliki kemampuan berpikir kritis, pemecahan masalah dan pemahaman yang lebih baik dari cabang matematika lain dengan membuat peserta didik memiliki tingkat keterampilan berpikir geometris yang tinggi (Aydoğdu \& Keşan, 2014).

Pemecahan masalah merupakan pilar penting dalam mempelajari matematika (Al-Migdady, 2014; Aydoğdu \& Keşan, 2014; NCTM, 2010). Mempelajari matematika diharuskan untuk berpikir agar mampu memahami konsep-konsep matematika yang dipelajari serta mampu menggunakan konsep-konsep tersebut secara tepat ketika menyelesaikan masalah (Saragih \& Habeahah, 2014; Muhassanah, 2014). Sesuai dengan tujuan pembelajaran geometri, maka peserta didik seharusnya menjadi pemecah masalah geometri yang baik. Tetapi dalam kenyataannya banyak peserta didik yang 
memiliki kesulitan dalam memecahkan masalah geometri (Abu \& Abidin, 2013; Muhassanah, 2014; Özerem, 2013).

Selain itu, data dari Balitbang (2012) menunjukkan bahwa daya serap ujian nasional tahun 2012 peserta didik SMP dan SMA di Jawa Timur maupun nasional untuk kompetensi geometri berada pada tingkat terendah dibandingkan kompetensi lainnya. Daya serap geometri pada ujian nasional SMP di Jawa Timur sebesar 75,95 sedangkan tingkat nasional sebesar 69,39. Daya serap geometri pada ujian nasional SMA di Jawa Timur sebesar 57,12 sedangkan tingkat nasional sebesar 63,77. Peserta didik lebih menganggap geometri lebih sulit dari pada kompetensi dalam matematika lainnya.

Sehubungan dengan kesulitan dalam belajar geometri maka guru sangat berperan penting dan aktif untuk menciptakan peserta didik yang memiliki kemampuan pemecahan masalah yang baik. Guru juga harus menguji tingkat berpikir geometri peserta didik berdasarkan teori Van Hiele untuk mengetahui sejauh mana peserta didik memahami materi geometri sehingga guru dapat mengatasi kesulitan peserta didik dalam belajar geometri.

Beberapa hasil penelitian tentang teori Van Hiele yang dilakukan sebelumnya menunjukkan kurangnya hasil belajar tentang geometri. Alex \& Mammen (2014) menyatakan bahwa mayoritas peserta didik kelas X SMA berada pada tingkat visualisasi. Khoiriyah, dkk (2014) menyatakan bahwa tingkat berpikir geometri peserta didik SMA berada pada tingkat analisis. Pinar (2014) menyatakan bahwa tingkat berpikir geometri peserta didik kelas IV, V, VI, dan VII berdasarkan teori Van Hiele masih rendah.

Berdasarkan latar belakang tersebut untuk meningkatkan kemampuan pemecahan masalah geometri maka guru perlu menganalisis proses pemecahan masalah geometri untuk mengetahui sejauh mana peserta didik memahami materi geometri. Sehingga penulis tertarik untuk menganalisis proses pemecahan masalah geometri berdasarkan teori Van Hiele karena penelitian sebelumnya hanya untuk mengetahui tingkat berpikir geometri berdasarkan teori Van Hiele belum sampai menganalisis proses pemecahan masalahnya.

\section{Rumusan Masalah}

Rumusan masalah yang akan dibahas dalam penelitian ini yaitu. 
1. Bagaimana proses pemecahan masalah geometri peserta didik yang mencapai tingkat visualisasi berdasarkan teori Van Hiele?

\section{METODE PENELITIAN}

Penelitian ini dirancang untuk mengeksplorasi dan mendeskripsikan proses pemecahan masalah geometri berdasarkan teori Van Hiele. Oleh karena itu jenis penelitian yang digunakan dalam penelitian ini adalah deskriptif eksploratif. Pendekatan yang digunakan dalam penelitian ini adalah pendekatan kualitatif. Subjek penelitian ini dibatasi pada peserta didik SMA yang mencapai tingkat visualisasi, analisis dan deduksi informal. Subjek tingkat deduksi formal dan rigor tidak bisa diungkap dikarenakan subjek tidak ada yang mencapai tingkat tersebut. Cara pengambilan subjek penelitian dalam penelitian ini yaitu peserta didik SMAN 2 Lumajang dites mengenai tingkat geometri berdasarkan teori Van Hiele diperoleh tingkat visualisasi, analisis dan deduksi informal. Kemudian setiap tingkat diambil dua peserta didik yang memiliki skor relatif sama serta yang dapat berkomunikasi dengan baik. Sehingga seluruh subjek penelitian terdapat enam peserta didik. Data yang diperoleh dalam penelitian ini berupa: a) data hasil tes geometri Van Hiele diperoleh dari tes geometri Van Hiele; b) data proses pemecahan masalah subjek penelitian diperoleh dari tes tertulis; c) wawancara setelah subjek menyelesaikan masalah geometri.

\section{HASIL DAN PEMBAHASAN}

Pada bab ini akan dipaparkan dan dianalisis data penelitian dari subjek yang terpilih. Subjek yang terpilih diantaranya yaitu AA dan DR yag mencapai tingkat visualisasi.

\section{Analisis Proses Pemecahan Masalah Subjek yang Mencapai Tingkat Visualisasi}

1. Mengidentifikasi masalah

Hasil pemecahan masalah subjek AA pada tahap mengidentifikasi masalah seperti pada Gambar 1, sedangkan subjek DR seperti Gambar 2 berikut.
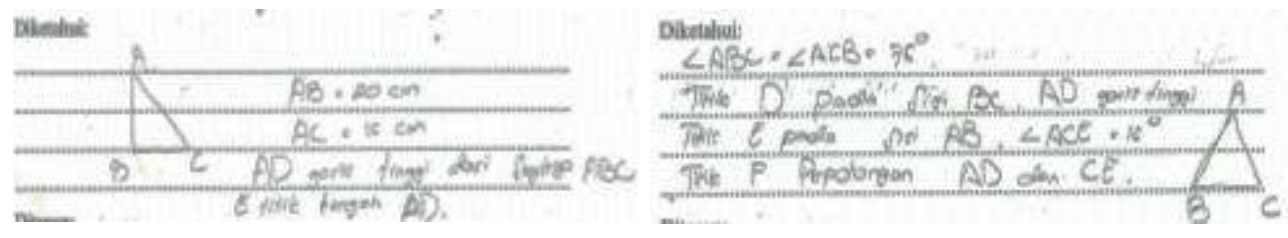
Gambar 1. Hasil tes tulis mengidentifikasi masalah oleh subjek AA

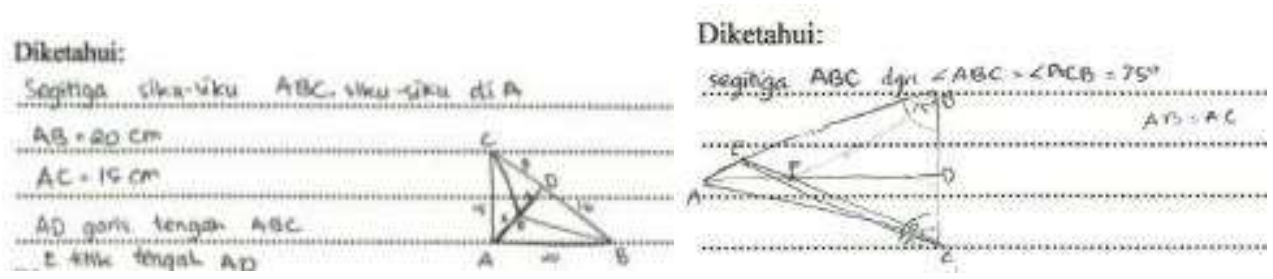

Gambar 2. Hasil tes tulis mengidentifikasi masalah oleh subjek DR

Berdasarkan hasil tes tulis pada tahap mengidentifikasi masalah, subjek yang mencapai tingkat visualisasi mengidentifikasi masalah pada permasalahan pertama dengan menyebutkan yang diketahui dari permasalahan. Sedangkan pada permasalahan kedua, kedua subjek dapat menyebutkan yang diketahui dari permasalahan namun kedua subjek kurang tepat dalam penulisan ukuran sudut. Subjek menuliskan $\angle A B C=\angle A C B=75^{\circ}$ sedangkan penulisan yang benar yaitu $u \angle A B C=u \angle A C B=75^{\circ}$. Hal ini dikarenakan kedua subjek sudah terbiasa menulis besar sudut seperti itu. Kesalahan penulisan besar sudut juga dikarenakan guru menuliskan besar sudut seperti itu.

Subjek yang mencapai tingkat visualisasi mentransformasikan yang diketahui dari permasalahan menjadi bangun geometri secara umum tanpa memberi keterangan mengenai sifat-sifatnya. Hasil wawancara dengan subjek AA mengenai pemahaman mengidentifikasi permasalahan pertama sebagai berikut

Peneliti : :"apa saja yang diketahui dari soal?"

Subjek $A A \quad$ :"segitiga $A B C$ siku-siku di $A . A B=20, A C=15, A D$ garis tinggi dalam segitiga $A B C, E$ titik tengah $A D$ ”

Sedangkan hasil wawancara dengan subjek DR yaitu.

Peneliti : "apa yang kamu pahami dari soal ini?"

Subjek DR : "segitiga siku-siku ABC, siku-sikunya di A. Dengan panjang $A B=20$ dan panjang $A C=15$. Ada garis $A D$ sebagai garis tinggi dari segitiga $A B C$ dan $E$ titik tengah $A D$ ”

Hasil wawancara dengan subjek AA pada permasalahan kedua yaitu sebagai berikut. 
Peneliti : :"apa saja yang diketahui dari soal?"

Subjek DR :"segitiga $A B C$ siku-siku di $A . A B=20, A C=15, A D$ garis tinggi dalam segitiga ABC, E titik tengah $A D$ ”

Sedangkan hasil wawancara dengan subjek DR yaitu

Subjek DR : "ini ada segitiga $A B C$, sudut $A B C$ sama dengan sudut $A C B$ itu 75․ Kemudian ada titik $D$ pada sisi BC sehingga $A D$ adalah garis tinggi. Kemudian ada titik E pada sisi AB sehingga sudut ACE itu $15^{\circ}$. Dan titik $F$ perpotongan $A D$ dan $C E$.

Hasil wawancara dengan kedua subjek mengenai identifikasi masalah geometri menyatakan bahwa kedua subjek dapat mengidentifikasi masalah dengan menyebutkan semua yang diketahui dari permasalahan dengan menggunakan bahasa pada soal. Meskipun subjek menyebutkan yang diketahui dari soal menggunakan bahasa soal namun subjek tidak menyebutkan satuan panjangnya. Berdasarkan hasil tes tulis dan hasil wawancara dengan kedua subjek yang mencapai tingkat visualisasi maka subjek yang mencapai tingkat visualisasi mengidentifikasi masalah geometri dengan menyebutkan yang diketahui dari permasalahan menggunakan bahasa soal.

2. Menentukan tujuan

Hasil pemecahan masalah subjek AA pada tahap menentukan tujuan seperti pada Gambar 3, sedangkan subjek DR seperti Gambar 4 berikut.
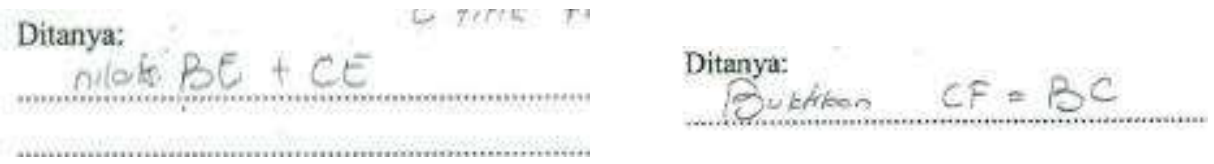

Gambar 3. Hasil tes tulis menentukan tujuan masalah oleh subjek AA

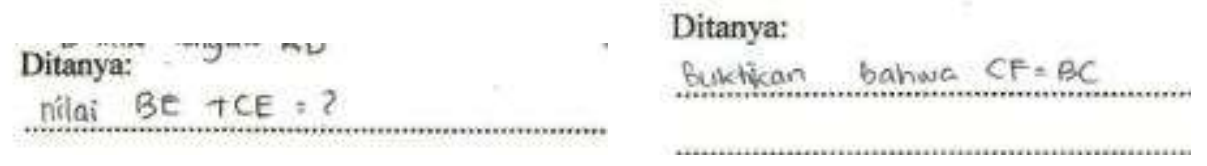

Gambar 4. Hasil tes tulis menentukan tujuan masalah oleh subjek DR

Subjek AA maupun subjek DR menentukan tujuan pada permasalahan pertama dan kedua dengan menyebutkan yang ditanyakan pada permasalahan yaitu menentukan jumlah dari panjang BE dan CE. Subjek yang mencapai 
tingkat visualisasi menentukan tujuan dalam soal pemecahan masalah menggunakan bahasanya sendiri. Hasil wawancara dengan subjek visualisasi mengenai menentukan tujuan dalam permasalahan pertama sebagai berikut

Peneliti : "yang ditanyakan dalam permasalahan tersebut apa?"

Subjek $D R \quad$ : "nilai $B E+C E$ "

sedangkan pada permasalahan kedua sebagai berikut

Peneliti :" yang ditanyakan apa?"

Subjek : "disuruh buktikan $C F=B C$ "

Berdasarkan hasil tes tulis dan hasil wawancara dengan kedua subjek dapat dikatakan bahwa subjek yang mencapai tingkat visualisasi menentukan tujuan dalam permasalahan geometri tersebut dengan menyebutkan yang ditanyakan pada permasalahan menggunakan bahasanya sendiri.

3. Mencari strategi yang mungkin

Hasil pemecahan masalah subjek AA pada tahap mencari strategi yang mungkin seperti pada Gambar 5, sedangkan subjek DR seperti Gambar 6 berikut.

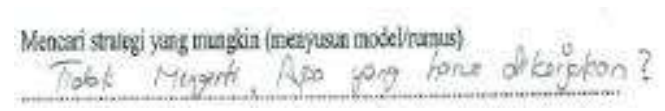

Mercari strategl yang mungkin (menyusun modelinumus)

Gambar 5. Hasil tes tulis mencari strategi yang mungkin untuk memecahkan masalah oleh subjek AA

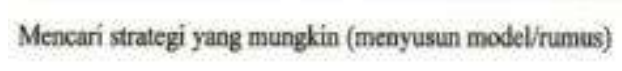

Mencari strategi yang mungkin (menyusun model/rumus)

$C A F=A C F=A S^{\circ}$

$A F C=10^{\circ}$

Gambar 6. Hasil tes tulis mencari strategi yang mungkin untuk memecahkan masalah oleh subjek DR

Subjek AA maupun subjek DR tidak menuliskan strategi yang mungkin untuk memecahkan masalah pertama maupun kedua. Subjek AA hanya menuliskan keterangan bahwa subjek AA tidak dapat menyelesaikan permasalahan tersebut. Subjek DR pada permasalahan pertama juga tidak 
menuliskan strategi yang mungkin sedangkan permasalahan kedua hanya menulis besar sudut yang belum diketahui tanpa ada cara.

Hasil wawancara dengan subjek AA mengenai mencari strategi yang mungkin dalam memecahkan permasalahan geometri pertama sebagai berikut

Peneliti : "kalau menyelesaikan BE+CE yang harus dikerjakan dulu apa?"

Subjek $A A \quad$ : "mencari BE+CE dulu bu”

Peneliti : "kalau cari BE, yang dikerjakan dulu apa?"

Subjek AA : "tidak bisa bu apa yang dikerjakan dulu”

Peneliti : "kalau cari BE tidak tahu, kemudian kalau cari CE bagimana?"

Subjek AA : "tidak bisa juga bu”

Peneliti : "mengapa tidak bisa?"

Subjek AA : "sulit bu,bingung. Ini ngerjainnya dari mana dulu, diapain"

Sedangkan hasil wawancara dengan subjek DR yaitu

Peneliti : "sekarang kalau menyelesaikan BE+CE, konsep yang dipakai apa aja?"

Subjek DR : "saya tidak tahu bu kalau mencari BE+CE nya itu gimana. Bingung nyarinya."

Hasil wawancara dengan kedua subjek menyatakan bahwa kedua subjek tidak mencari strategi yang mungkin digunakan dalam memecahkan masalah dikarenakan kedua subjek tidak memahami permasalahan tersebut sehingga kedua subjek tidak mengetahui langkah demi langkah apa yang harus dikerjakan. Berdasarkan hasil tes tulis dan hasil wawancara, subjek yang mencapai tingkat visualisasi tidak mencari strategi yang mungkin digunakan dalam memecahkan masalah.

Subjek AA dan subjek DR tidak menyusun strategi yang mungkin untuk memecahkan masalah geometri. Sehingga subjek yang mencapai tingkat visualisasi tidak dapat menyelesaikan tahap pemecahan masalah IDEAL untuk tahap melaksanakan strategi serta mengkaji kembali dan mengevaluasi pengaruhnya. 
Berdasarkan hasil tes tulis pemecahan masalah dan hasil wawancara, subjek yang mencapai tingkat visualisasi tidak melaksanakan setiap langkah pemecahan masalah IDEAL. Proses subjek dalam memecahkan masalah hanya menyebutkan yang diketahui dari permasalahan serta yang ditanyakan pada permasalahan. Kedua subjek tidak memahami langkah demi langkah apa yang harus dilakukan untuk menyelesaikan masalah geometri tersebut. Hal ini dikarenakan subjek yang mencapai tingkat visualisasi memahami bangun berdasarkan penampakan bentuknya yang utuh. Subjek dapat mengidentifikasi bagian-bagian bangun tetapi subjek tidak berpikir tentang sifat-sifat sebagai karakteristik bangun serta tidak membuat generalisasi tentang bangun atau menggunakan bahasa yang relevan.

\section{PEMBAHASAN}

Hasil penelitian yang telah diuraikan di atas menunjukkan bahwa proses pemecahan masalah geometri yang dimiliki subjek berdasarkan tingkat berpikir Van Hiele berbeda-beda. Subjek yang mencapai tingkat visualisasi hanya bisa menyelesaikan pada langkah mengidentifikasi masalah dengan membuat bangun secara umum dan menentukan tujuan dengan menggunakan bahasa pada soal serta kesalahaan pada penulisan ukuran sudut. Hal ini sesuai dengan Noriza, dkk (2015) yang menyatakan bahwa peserta didik pada tingkat visualisasi tidak dapat membuat model matematika, hal ini terlihat dari kemampuan untuk membuat sketsa berdasarkan unsurunsur yang sudah dikenal. Peserta didik membuat bentuk geometri berdasarkan penampilan fisik secara keseluruhan (Muhassanah, dkk, 2014). Selain itu peserta didik tidak dapat merencanakan dengan baik untuk memecahkan masalah dikarenakan peserta didik mengidentifikasi bentuk geometri secara keseluruhan sehingga tidak dapat menentukan rumus yang digunakan untuk memecahkan masalah.

Berdasarkan hasil pemaparan proses pemecahan masalah berdasarkan tingkat Van Hiele menunjukkan bahwa proses pemecahan masalah subjek berbeda-beda. Hal ini sesuai dengan Muhassanah, dkk (2014) yang menunjukkan keterampilan geometri yang dimiliki peserta didik berdasarkan tingkat berpikir Van Hiele berbeda-beda dan berurutan sesuai dengan tingkat berpikir Van Hiele. Abdussakir (2010) menyatakan 
bahwa salah satu tujuan pembelajaran geometri adalah agar peserta didik dapat menjadi pemecah masalah yang baik. Meskipun demikian, yang terjadi selama ini adalah geometri merupakan materi yang sulit dipahami dan cenderung dibenci oleh kebanyakan peserta didik. Seperti yang diutarakan oleh Adolphus (2011) bahwa materi matematika yang dianggap sulit dan ditakuti siswa dalam pelajaran matematika adalah materi geometri. Hal ini mengakibatkan siswa enggan belajar geometri dan pada akhirnya tujuan pembelajaran geometri untuk mengembangkan kemampuan pemecahan masalah tidak dapat dicapai.

Kualitas pengetahuan peserta didik tidak ditentukan dari akumulasi pengetahuan peserta didik atau seberapa banyak pengetahuan yang dimilikinya, tetapi lebih ditentukan oleh proses berpikir yang digunakan. Hal ini sesuai dengan Azimi dan Irawan (2012) bahwa penerapan pembelajaran geometri Van Hiele dapat meningkatkan tahap berpikir siswa dari tahap visualisasi ke tahap analisis. Sehingga melalui pembelajaran yang sesuai dengan tingkat berpikir peserta didik maka peserta didik dapat memecahkan masalah dengan baik.

\section{SIMPULAN}

Berdasarkan analisis dan pembahasan yang telah diuraikan pada Bab IV diperoleh kesimpulan sebagai berikut

1. Pemecahan masalah pada geometri peserta didik yang mencapai tingkat berpikir visualisasi adalah dengan mengidentifikasi masalah dan menentukan tujuan dengan menggunakan bahasa soal. Peserta didik tidak mencari strategi yang mungkin, melaksanakan strategi maupun mengkaji kembali dan mengevaluasi pengaruhnya.

2. Pemecahan masalah pada geometri peserta didik yang mencapai tingkat berpikir analisis adalah melalui kelima langkah pemecahan masalah IDEAL dengan menggunakan bahasanya sendiri namun kurang sistematis. Subjek yang mencapai tingkat analisis memecahkan masalah menggunakan sifat-sifat bangun yang sudah diketahui namun tidak memformulasikan secara formal.

3. Pemecahan masalah pada geometri peserta didik yang mencapai tingkat berfikir deduksi informal adalah melalui kelima langkah pemecahan masalah IDEAL 
dengan sistematis dan menggunakan bahasanya sendiri. Peserta didik memecahkan masalah secara runtut dan sistematis pada setiap cara atau langkah yang digunakan.

\section{DAFTAR PUSTAKA}

Abdullah, A. H \& Zakaria, E. (2013). Enhancing Students' Level of Geometric Thinking Through Van Hiele's Phase-based Learning. Indian Journal of Science and Technology. Vol. 6, No. 5

Abu, M. S. \& Abidin, Z. Z. (2013). Improving the Levels of Geometric Thinking of Secondary School Students Using Geometry Learning Video based on Van Hiele Theory. International Journal of Evaluation and Research in Education (IJERE). Vol. 2, No. 1

Alex, J. K. \& Mammen, J. (2012). A Survey of South African Grade 10 Learners' Geometric Thinking Levels in Terms of the Van Hiele Theory. Anthropologist. Vol. 14. No. 2

Al-Migdady, A. M. (2014). Skilled-Unskilled mathematical Problem Solvers: Jordanian-Students' Differences in Solving Geometrical Problems. European Scientific Journal. Vol. 10, No. 25

Aydoğdu, M. Z \& Keşan, C. (2014). A Research On Geometry Problem Solving Strategies Used By Elementary Mathematics Teacher Candidates. Journal of Educational and Instructional Studies. Vol. 4, No. 1

Bahmaei, F. (2011). Mathematical modelling in primary school, advantages and challenges. Journal of Mathematical Modelling and Application. Vol.1, No. 9

Balitbang. (2012). Daya Serap Ujian Nasional Tahun 2012

Breyfogle, M. L. \& Lynch, C. M. (2010). To Analyze Students' Geometric Thinking,Use Both Formative and Summative Assessments and Move Students along the Van Hiele Model of Thought. Mathematicas Teaching in the Middle School. Vol. 16. No. 4

Khoiriyah, N, et al. (2013). Analisis Tingkat Berpikir Siswa Berdasarkan Teori Van Hiele Pada Materi Dimensi Tiga Ditinjau Dari Gaya Kognitif Field Dependent dan Field Independent. Jurnal Pendidikan Matematika Solusi. Vol. 1, No. 1 
Kutluca, T. (2013). The Effect Of Geometry Instruction with Dynamic Geometry Software; Geogebra on Van Hiele Geometry Understanding Levels of Students. Academic Journals. Vol. 8. No. 17

Mohamed, L \& Waheed, H. (2014). Secondary Students' Attitude towards Mathematics in a Selected School of Maldives. International Journal of Humanities and Social Science. Vol. 1, No. 15

Muhassanah, N, et al. (2014). Analisis Keterampilan Geometri Siswa dalam Memecahkan Masalah Geometri Berdasarkan Tingkat Berpikir Van Hiele. Journal Elektronik Pembelajaran Matematika. Vol. 2, No. 1

NCTM. (2010). A Research on Geometry Problem Solving Strategies Used by Elementary Mathematics Teacher Candidates

Özerem, A. (2013). Misconceptions In Geometry And Suggested Solutions For Seventh Grade Students. International Journal of New Trends in Arts, Sport \& Science Education. Vol. 1, No. 4

Patsiomitou, S. \& Emvalotis, A. (2010). Students Movement Through Van Hiele Levels in a Dynamic Geometry Guided Reinvention Process. Journal of Mathematics and Technology.

Pinar, A. (2014). Predictor Variables For Primary School Students Related To Van Hiele Geometric Thinking. Journal of Theory and Practice in Education. Vol. 10, No.1

Prasetya, A. \& Widodo, K. (2012). Model Ideal Problem Solving untuk Pencapaian Kemampuan Pemecahan Masalah di Kelas Olimpiade. Lembaran Ilmu Kependidikan. Vol. 41. No. 1

Saragih, S \& Habeahan, W. L. (2014). The Improving of Problem Solving Ability and Students'Creativity Mathematical by Using Problem Based Learning in SMP Negeri 2 Siantar. Journal of Education and Practice. Vol. 5, No. 35

Susiana, E. (2010). IDEAL Problem Solving dalam Pembelajaran Matematika. Jurnal Matematika Kreatif-Inovatif. Vol. 1, No. 2

Vojkuvkova, I. (2012). The van Hiele Model of Geometric Thinking. WDS'12 Proceedings of Contributed Papers 